\title{
Monitoring the correction of glycogen storage disease type 1a in a mouse model using $\left[{ }^{18} \mathrm{~F}\right] \mathrm{FDG}$ and a dedicated animal scanner
}

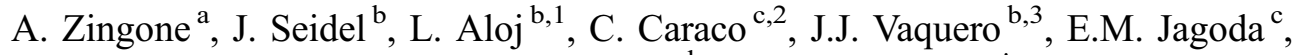 \\ J.Y. Chou ${ }^{\mathrm{a}}$, M.V. Green ${ }^{\mathrm{b}}$, W.C. Eckelman ${ }^{\mathrm{c}, *}$ \\ ${ }^{\mathrm{a}}$ National Institute of Child Health and Development, Bethesda MD 20892 USA \\ ${ }^{\mathrm{b}}$ Department of Nuclear Medicine, National Institutes of Health, Bethesda MD 20892 USA \\ ${ }^{\mathrm{c}}$ PET Department, National Institutes of Health, Bethesda MD 20892 USA
}

\begin{abstract}
Monitoring gene therapy of glycogen storage disease type 1a in a mouse model was achieved using $\left[{ }^{18} \mathrm{~F}\right] \mathrm{FDG}$ and a dedicated animal scanner. The G6Pase knockout (KO) mice were compared to the same mice after infusion with a recombinant adenovirus containing the murine G6Pase gene (Ad-mG6Pase). Serial images of the same mouse before and after therapy were obtained and compared with wild-type (WT) mice of the same strain to determine the uptake and retention of $\left[{ }^{18} \mathrm{~F}\right] \mathrm{FDG}$ in the liver. Image data were acquired from heart, blood pool and liver for twenty minutes after injection of $\left[{ }^{18} \mathrm{~F}\right] \mathrm{FDG}$. The retention of $\left[{ }^{18} \mathrm{~F}\right] \mathrm{FDG}$ was lower for the WT mice compared to the KO mice. The mice treated with adenovirus-mediated gene therapy had retention similar to that found in age-matched WT mice. These studies show that FDG can be used to monitor the G6Pase concentration in liver of WT mice as compared to G6Pase KO mice. In these mice, gene therapy returned the liver function to that found in age matched WT controls as measured by the FDG kinetics in the liver compared to that found in age matched wild type controls.
\end{abstract}

Keywords: Glycogen storage disease type 1a; Mouse; $\left[{ }^{18} \mathrm{~F}\right] \mathrm{FDG}$; G6Pase

\footnotetext{
* Corresponding author. PET Department, Warren Grant Magnuson Clinical Center, Bld 10 Rm 1C495, 10 Center Drive MSC 1180, Bethesda MD 20892 USA. Tel.: +1 301496 6455; fax: +1 3014023521.

E mail address: eckelman@nih.gov (W.C. Eckelman).

${ }^{1}$ Current address: Centro per la Medicina Nucleare, CNR, Napoli, Italy.

${ }^{2}$ Current address: Istituto di Medicina Sperimentale e Biotecnologie, CNR, Cosenza, Italy.

${ }^{3}$ Current address: Hospital General Universitario Gregorio Maranon, Madrid, Spain.
} 


\section{Introduction}

Glucose-6-Phosphatase (G6Pase) [1], most abundantly found in liver and kidney, catalyzes the last step of both gluconeogenesis and glycogenolysis. This enzyme is a key protein in the regulation of glucose homeostasis. Its function is to dephosphorylate glucose-6-phosphate (G6P), so that free glucose can be transported out of cells and released into the blood. Thus, the activity of this enzyme controls liver glucose production. Defects of the G6Pase enzyme system cause glycogen storage disease type 1 (GSD-1), which manifests with severe hypoglycemia, hepatomegaly, hyperlipidemia, and hyperuremia. If no therapy is implemented, very few GSD-1 patients can live to 20 years of age. GSD-1 affects 1 in 100,000 live birth. Morbidity and mortality have been improved because of successful dietary therapy.

The G6Pase enzyme system is associated with the endoplasmic reticulum and has multiple components [2]. Current understanding of this system indicates that G6P is transported into the microsome by a G6P transporter (G6PT). Once inside the microsome the G6Pase catalytic unit dephosphorylates G6P and finally phosphate and glucose are transported out of the microsome via specific transport proteins [3]. Accordingly, GSD-1 was divided into four subgroups, corresponding to defects in: the G6Pase catalytic unit (GSD-1a), the G6P transporter (GSD-1b), the putative phosphate/ pyrophosphate transporter (GSD-1c), and the putative glucose transporter (GSD-1d) [4]. The cDNA and gene for both the G6Pase catalytic unit [1,5] and G6PT [6-8] have been isolated and characterized and the molecular bases of GSD-1a [1] and GSD-1b [8] have been established. The requirement for both the G6Pase catalytic unit and G6PT has recently been demonstrated in cell culture [9].

$\left[{ }^{18} \mathrm{~F}\right]$-2-fluoro-2-deoxyglucose $\left(\left[{ }^{18} \mathrm{~F}\right]-\mathrm{FDG}\right)$ is a glucose analog currently utilized for positron emission tomography (PET) imaging studies in humans. FDG uptake has been used for many years to measure in vivo regional glucose utilization [10]. This tracer competes with glucose for phosphorylation by hexokinase or glucokinase. After it is phosphorylated, FDG-6-phosphate (FDG6P) does not undergo glycolysis. In tissues with elevated glucose metabolic rates, such as tumors, with low or absent dephosphorylating activity, FDG6P is trapped inside cells. This property allows for imaging of areas with increased FDG retention and has been extensively applied to visualize, stage and monitor progression of tumors [11]. On the other hand, in organs such as the liver, FDG is taken up and rapidly released, presumably due to the presence and activity of the G6Pase enzyme [12]. Images in a single patient with GSD-1 indicate that FDG is more avidly retained in the liver compared to normal subjects [13]. The pharmacokinetics of FDG, developed from the seminal work by Sokoloff using $\left[{ }^{14} \mathrm{C}\right]$ deoxyglucose, can be described by the two tissue compartment model $[14,15]$. The current understanding of FDG metabolism is that the $\mathrm{k}_{4}$ parameter (the rate of hydrolysis of G6P) is tightly linked to the presence and activity of the G6Pase enzyme system. Therefore, in vivo measurement of $\mathrm{k}_{4}$ for FDG may provide a non invasive quantitative method to evaluate liver G6Pase function and also be a tool to monitor the effectiveness of gene therapy in patients with GSD type 1.

Recently a mouse model of GSD-1a has been generated by gene targeting [16]. The G6Pase-knockout (KO) mice manifest essentially the same phenotype as human GSD-1a patients and have been used to evaluate the gene replacement therapy for this disorder [17]. The results demonstrate that a single administration of a recombinant adenovirus vector can alleviate the clinical manifestations of GSD-1a in mice, suggesting that this disorder in humans can potentially be corrected by gene therapy. Therefore, it was of interest to determine if G6Pase deficiency in these $\mathrm{KO}$ animals could be monitored by external imaging using a projection imaging PET camera especially designed for small animal imaging [18]. 
FDG uptake and release is affected exclusively by transport, phosphorylation and dephosphorylation because it cannot undergo further glycolysis. Sadiq et al. found that the glucose transporter, GLUT 1, was similar from day 1 to day 27 in normal mice, whereas the GLUT 2 decreased from a high at day 1 to a low at day 14 and 27 [19]. Glucokinase concentrations were similar at day 1 and day 7 but increased by $33 \%$ by day 14 and 27 . Therefore, we expected that FDG would be transported and phosphorylated in a normal fashion over the lifetime of the mice. It has been shown that microsomal G6Pase activity was first detectable in rat liver at 17 days gestation and enzymatic activity increased rapidly after birth, before leveling off to adult levels [20-22]. In the mouse, hepatic G6Pase mRNA and enzymatic activity were first detected by 18 days gestation, and at parturition, the level of G6Pase mRNA increased markedly before leveling off to steady-state adult levels [22]. The age at which steady-state G6Pase mRNA occurs is approximately day 4 after birth. We therefore expected that the FDG would be transported into the hepatocytes, phosphorylated, and dephosphorylated essentially independent of age of the mouse. Our hypothesis is that the G6Pase KO mice would have higher retention of FDG compared to the wild-type, and after gene therapy, the KO mice would process FDG in a similar manner to that observed in the wild type (WT) mice.

\section{Materials and methods}

\section{G6Pase KO mice}

All animal studies were conducted under an animal protocol approved by the NICHD Animal Care and Use Committee. Starting within the first postnatal day, glucose therapy, consisting of intraperitoneal injection of $25-100 \mu \mathrm{l}$ of $10 \%$ glucose every $8 \mathrm{~h}$ was administered to the G6Pase ${ }^{-/-}$mice. Mice that passed weaning were given glucose injection, unrestricted access to water containing polycose (5\%), and Mouse Chow (Zeigler Bros., Inc., Gardners, PA.).

\section{Infusion of mice with Ad-mG6Pase}

Two-week-old G6Pase KO mice [16] were infused with $0.1 \mathrm{ml}$ of Ad-mG6Pase containing $2 \times 10^{9}$ plaque forming units (PFU) via the retro-orbital vein [17]. Glucose therapy was terminated immediately in Ad-mG6Pase-infused G6Pase KO mice and the weaning mice were given Mouse Chow ad libitum.

\section{Imaging studies}

FDG was prepared using a standard method [23]. The mice were injected with $275 \mu \mathrm{Ci}$ with a range of 131 to $576 \mu \mathrm{Ci}$. The knockout mice ranged from $5 \mathrm{~g}$ to $17 \mathrm{~g}$ and the control mice ranged from 8 to 18 $\mathrm{g}$ with one normal control at $25 \mathrm{~g}$. The animal imaging system (PiPET) has been described previously [18]. Each detector consists of a $26 \times 22$ array of bismuth germanate (BGO) crystals coupled to a Hamamatsu R3941 position-sensitive photomultiplier tube. Tomographic resolution is FWHM =2.1 mm and central point source sensitivity without energy thresholding is $130 \mathrm{cps} / \mu \mathrm{Ci}$. The imaging study was performed in each mouse after configuring the detector pair for planar imaging. The animal was placed on the imaging table, centered within the field-of-view, injected with $\left[{ }^{18} \mathrm{~F}\right] \mathrm{FDG}$ in a retroorbital vein and imaging immediately begun. Image data were acquired for 20 minutes in "list mode" and formatted into 
Table 1

Comparison of $\left[{ }^{18}\right.$ F]FDG Uptake in Awake and Anesthetized Mice after 20, 60, and $90 \mathrm{~min}$



$1 \%$ Injected Dose (ID)/g was normalized to a $20 \mathrm{~g}$ mouse.

2 Each mouse was anesthetized IP with Ketamine $(50 \mathrm{mg} / \mathrm{Kg}) / \mathrm{Xylazine}(2 \mathrm{mg} / \mathrm{Kg})$.

${ }^{3}$ Mean \pm Standard deviation ( $\mathrm{n} \quad 3 \quad 5$ mice).

sequential 10 -second frames. This image sequence was then analyzed to quantify the time variation of radioactivity in the liver and heart. Time-activity curves were obtained from both structures by placing a region-of-interest over the apparent center of the heart and another over the upper right lobe of the liver. Both of these regions were small compared to the apparent size of both structures. The time-activity curves for the heart were analyzed using a two exponential fit in Kaleidagraph (Synergy Sofware, Inc, Brentwood TN). The errors represent the standard error values of the parameters.

These time-activity curves were then used to create Patlak and Logan plots for each animal. The Patlak plot is useful for characterizing ligands that bind irreversibly and are essentially trapped for the time course of the scanning procedure [24,25]. The Logan plot is useful for analysis of reversible systems where the slope of the plot yields the volume of distribution [26].

\section{Biodistribution studies (Table 1)}

Tumor bearing mice (nu/nu Balb/c) or Balb/c mice, which were awake or anesthetized [IP with Ketamine $(50 \mathrm{mg} / \mathrm{Kg}) /$ Xylazine $(2 \mathrm{mg} / \mathrm{Kg})]$, were injected intravenously with 10 to $20 \mu \mathrm{Ci}$ of $\left[{ }^{18} \mathrm{~F}\right] \mathrm{FDG}$. The awake or anesthetized groups were sacrificed at 20,60, or $90 \mathrm{~min}$ following the injection. Blood and tissue samples were removed and counted in a Wallac gamma counter. The results are expressed as $\%$ injected dose $/ \mathrm{g}$ of tissue $(\% \mathrm{ID} / \mathrm{g})$ normalized to a $20 \mathrm{~g}$ mouse.

\section{Results and discussion}

We have completed imaging studies on a series of mice that included 20 WT mice, 6 G6Pase KO mice, and $4 \mathrm{KO}$ mice after two weeks of adenovirus-mediated gene therapy [17]. Each mouse was injected with $\left[{ }^{18} \mathrm{~F}\right] \mathrm{FDG}$ and scanned continuously for 20 minutes using the PiPET system. The time activity curve over the liver was compared with radioactivity in the heart blood pool. Since plasma contains only $\left[{ }^{18} \mathrm{~F}\right] \mathrm{FDG}$, the heart radioactivity was used as the input function.

All three sets of mice (WT, KO, and KO after gene therapy) exhibited reversible binding in the mouse liver based on the observation of a plateau on the Patlak plot and a straight line on the Logan plot. This can be explained by the presence of non-specific phosphatases because the G6Pase activity in the KO mice was only $\sim 1 \%$ of the activity found in the wild type mice [17]. Because the Patlak plot does not 
give accurate volumes of distribution with reversible ligands, we concentrated on interpreting the data by using the Logan Plot.

The first observation was that the slopes of the Logan plots for the WT group was dependent on the weight of the animal (Fig. 1). The correlation of the volume of distribution was 0.039 times the weight of the WT mouse $(\mathrm{R}=0.85)$. We then compared the Logan plot slope for WT and KO animals with body weights between 5 and $10 \mathrm{~g}$. The average slope for the WT was $1.32 \pm 0.041$ whereas the average slope for the KO mice was significantly higher $(1.47 \pm 0.045)$. The box graph (Fig. 2) shows the distribution of the Logan slopes for the WT and KO mice. For a group of WT animals with body weights between 5 and 10 grams, the slope from the Logan plot of 12 mice was between 1.1 and 1.3 while three other mice had higher values at $1.45-1.55$.

The Logan slope for the group of treated KO mice was similar to that obtained for the WT (Fig. 1). By the nature of the experiment, the treated $\mathrm{KO}$ mice weighed from between 13.5 to $17.1 \mathrm{~g}$ body weight. The correlation of the Logan slope and the body weight was $\mathrm{y}=0.96+0.04 \mathrm{x}$ with $\mathrm{R}=0.83$ for the WT and $0.76+0.59 \mathrm{x}$ with a $\mathrm{R}=0.86$ for the KO.

The volume of distribution as given by the slope of the Logan plot equals $\mathrm{K}_{1} / \mathrm{k}_{2}\left(1+\mathrm{k}_{3} / \mathrm{k}_{4}\right)$. The change in slope could be caused by changes in any of the four parameters constituting the equation for the slope. The partition coefficient $\left(\mathrm{K}_{1} / \mathrm{k}_{2}\right)$ is not a function of blood flow and unlikely to change among the three groups. In weight-matched animals, the concentration of glucokinase should be similar and therefore $\mathrm{k}_{3}$ should not be different among the groups. The increase in slope in the KO mice is mostly likely related to a decrease in $\mathrm{k}_{4}$ caused by a decrease in G6Pase activity. The $\mathrm{KO}$ animals after gene therapy had Logan plot slopes that were larger than the first two groups, but they were statistically

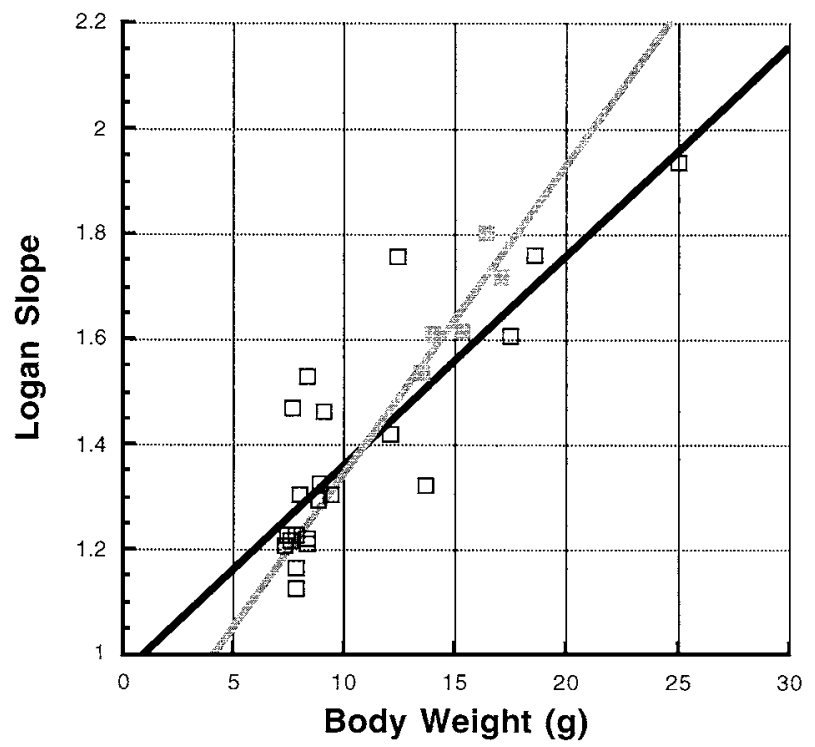

Fig. 1. The Logan slope for the group of treated KO mice (solid squares) and the WT (open squares). By the nature of the experiment, the treated $\mathrm{KO}$ mice weighed between 13.5 to $17.1 \mathrm{~g}$ body weight. The correlation of the Logan slope and the body weight was y $\quad 0.96+0.04 \mathrm{x}$ with $\mathrm{R} \quad 0.83$ for the WT and $0.76+0.59 \mathrm{x}$ with $\mathrm{R} \quad 0.86$ for the KO. 


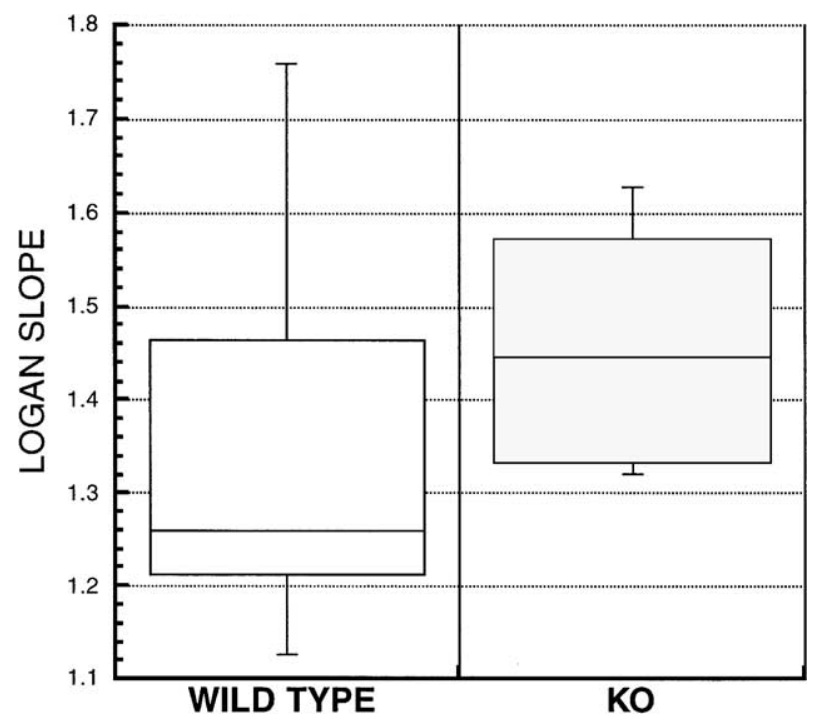

Fig. 2. The Logan plot slope for WT and KO animals with body weights between 5 and $10 \mathrm{~g}$. The average slope for the WT was $1.32 \pm 0.041$ whereas the average slope for the KO mice was significantly higher $(1.47 \pm 0.045)$. Each box encloses $50 \%$ of the data with the median value of the variable displayed as a line. The top and bottom of the box mark the limits of $\pm 25 \%$ of the variable population. The lines extending from the top and bottom of each box mark the minimum and maximum values within the data set that fall within an acceptable range.

similar to WT mice of the same weight (they were older at the time of scanning because of the serial nature of the experiment).

We have two possible explanations for the change in slope of the Logan plots: (1) FDG is not phosphorylated in any of the groups and the reversible binding is due to $\mathrm{K}_{1} / \mathrm{k}_{2}$ with no $\mathrm{k}_{3}$ and $\mathrm{k}_{4}$; that is, the FDG is taken up by the cell and then released. However, the increase in slope of the G6Pase KO mice would not be easily explained by this mechanism because it would require an increase in $\mathrm{K}_{1} / \mathrm{k}_{2}$, which is flow independent. The second explanation for reversible binding is a constant partition coefficient $\left(\mathrm{K}_{1} /\right.$ $\mathrm{k}_{2}$ ) and a decrease in $\mathrm{k}_{4}$ caused by the KO procedure. Since the kinetics of FDG in untreated KO mice are still reversible, other phosphatases must have hydrolyzed the G6P to some extent. Certainly the KO mice had glycogen deposits in the liver and kidney so phosphatase activity was decreased, but not to the extent that the kinetics of FDG become irreversible. Since the volume of distribution increased in the KO mice, a decrease in $\mathrm{k}_{4}$ is most consistent with the data.

The average rate constant for the fast component of the radioactivity collected from the heart blood pool in the WT was $0.030 / \mathrm{sec} \pm 0.003 / \mathrm{sec}$ where as the fast component for the $\mathrm{KO}$ was $0.065 / \mathrm{sec} \pm$ $0.007 / \mathrm{sec}$ and for the treated KO $0.085 / \mathrm{sec} \pm 0.007 / \mathrm{sec}$. The average rate constants for the slow components of the radioactivity collected from the heart blood pool in the WT, KO and treated KO were similar. We also have observed that mice under anesthesia had low heart muscle uptake when compared to awake animals and even at the end of our scan period of $20 \mathrm{~min}$, the blood still contains more $\left[{ }^{18} \mathrm{~F}\right] \mathrm{FDG}$ than the heart muscle (Table 1). This lower uptake should increase the percentage of radioactivity measured in the blood pool. In general, the integral from the heart blood pool appears to be similar between the KO mice and the treated KO mice and the uptake in the heart muscle compared to that in the heart blood pool is low. However, the Logan plot takes into account differences in input 
function in the calculation of the volume of distribution. Gallagher et al. [12] carried out the early studies with FDG by sacrificing rats and counting tissue. More recently, imaging studies of liver and blood using FDG have been carried out in rodents. Green et al. [27] studied the biodistribution of FDG in mice and concluded that the input function could be obtained from monitoring the liver, but that heart TAC could not be used presumably due to myocardial uptake of FDG. However, they were not using a dedicated animal scanner in that study. Other investigators including Kallinowski et al. [28] and Hawkins et al. [29] have been able to use the mouse left ventricle blood pool as the input function for FDG studies. They both used high-resolution, dedicated animal PET scanners. Hawkins et al. obtained direct serial retroorbital blood samples and compared them with arterial concentrations derived from imaging data and with arterial sampling obtained by Kallinowski et al. This also suggests the left ventricle blood pool radioactivity may be used as the input function. Lapointe et al. [30] collected eight blood samples of 10 $\mu \mathrm{L}$ in mice with the help of a computer-controlled microvolumetric sampler. The amount in the blood was compared with the amount of FDG in the tumor, but the blood samples were not compared with time-activity curves of the blood pool.

Choi et al. [31] showed that the volume of distribution in humans in both fasting subjects and postglucose was similar and the liver blood volume was increased in fasted subjects compared to postglucose subjects [32]. However, it is clear that plasma glucose levels can affect myocardial uptake of FDG and this in turn could affect the determination of the input function in these studies. In the three groups of mice used in this study, Zingone et al. showed that the glucose levels were lower in the KO mice $(66.6 \pm 15.6 \mathrm{mg} / \mathrm{dl})$ than in the wild type $(213.7 \pm 12.7 \mathrm{mg} / \mathrm{dl})$ and $\mathrm{KO}$ mice treated with adenovirus vector [17]. The treated $\mathrm{KO}$ group reached a peak plasma glucose level at 42 days of $155.8 \pm$ $11.4 \mathrm{mg} / \mathrm{dl}$. This is in spite of the $\mathrm{KO}$ mice receiving glucose injections until weaning and having access to high starch mouse chow. There are no published studies describing how a change in glucose level affects uptake in the mouse myocardium. We did not subtract blood radioactivity from the time-activity curves over the liver. The liver was smallest in the wild type animals compared to the KO treated animals and the $\mathrm{KO}$ untreated animals. However, no information on the blood volumes was available.

These studies show that FDG can be used to monitor the G6Pase concentration in liver of WT mice as compared to G6Pase KO mice. Furthermore, FDG can be used to monitor the effects of gene therapy. In these mice, gene therapy returned the liver function to that found in age matched WT controls as measured by the FDG kinetics in the liver compared to that found in age matched wild type controls.

\section{References}

[1] Lei KJ, Shelly LL, Pan CJ, Sidbury JB, Chou JY. Mutations in the glucose 6 phosphatase gene that cause glycogen storage disease type 1a. Science 1993;262:580 3.

[2] Chen TB, Brenner NJ, Gibson RE, Burns HD, Chang RSL. Characterization of the binding of [125I]L 735,286: a new nonpeptide angiotensin II AT1 receptor radioligand. Life Sciences 1995;56:629 34.

[3] Arion WJ, Lange AJ, Walls HE, Ballas LM. Evidence for the participation of independent translocation for phosphate and glucose 6 phosphate in the microsomal glucose 6 phosphatase system. Interactions of the system with orthophosphate, inorganic pyrophosphate, and carbamyl phosphate. J Biol Chem 1980;255:10396 406.

[4] Chen Y T, Burchell A. In: Scriver Cr, Beaudet Al, Sly Ws, et al, editors. Glycogen Storage Diseases. 7th ed. New York: McGraw Hill; 1995. p. 93566.

[5] Shelly LL, Lei KJ, Pan CJ, Sakata SF, Ruppert S, Schutz G, Chou JY. Isolation of the gene for murine glucose 6 phosphatase, the enzyme deficient in glycogen storage disease type 1A. J Biol Chem 1993;268:21482 5. 
[6] Gerin I, Veiga da Cunha M, Achouri Y, Collet JF, Van Schaftingen E. Sequence of a putative glucose 6 phosphate translocase, mutated in glycogen storage disease type Ib. FEBS Lett 1997;419:235 8.

[7] Lin B, Annabi B, Hiraiwa H, Pan CJ, Chou JY. Cloning and characterization of cDNAs encoding a candidate glycogen storage disease type 1b protein in rodents. J Biol Chem 1998;273:31656 70.

[8] Hiraiwa H, Pan CJ, Lin B, Moses SW, Chou JY. Inactivation of the glucose 6 phosphate transporter causes glycogen storage disease type 1b. J Biol Chem 1999;274:5532 6.

[9] Caraco C, Aloj L, Chen LY, Chou JY, Eckelman WC. Cellular release of $\left[{ }^{18} \mathrm{~F}\right] 2$ fluoro 2 deoxyglucose as a function of the glucose 6 phosphatase enzyme system. J Biol Chem 2000;275:18489 94.

[10] Phelps ME, Huang SC, Hoffman EJ, Selin C, Sokoloff L, Kuhl DE. Tomographic measurement of local cerebral glucose metabolic rate in humans with (F 18)2 fluoro 2 deoxy D glucose: validation of method. Ann Neurol 1979;6:371 88.

[11] Conti PS, Lilien DL, Hawley K, Keppler J, Grafton ST, Bading JR. PET and $\left[{ }^{18}\right.$ F] FDG in oncology: a clinical update. Nucl Med Biol 1996;23:717 36.

[12] Gallagher BM, Fowler JS, Gutterson NI, MacGregor RR, Wan CN, Wolf AP. Metabolic trapping as a principle of radiopharmaceutical design: some factors resposible for the biodistribution of $\left[{ }^{18} \mathrm{~F}\right] 2$ deoxy 2 fluoro D glucose. J Nucl Med 1978;19:1154 61.

[13] Gjedde A. In: Wagner H, Szabo ZBuchanan Jw, editors. Glucose Metabolism. 2nd ed. WB Saunders; 1995. p. 5471.

[14] Sokoloff L, Reivich M, Kennedy C, Des Rosiers MH, Patlak CS, Pettigrew KD, Sakurada O, Shinohara M. The [14C]deoxyglucose method for the measurement of local cerebral glucose utilization: theory, procedure, and normal values in the conscious and anesthetized albino rat. J Neurochem 1977;28:897 916.

[15] Reivich M, Kuhl D, Wolf A, Greenberg J, Phelps M, Ido T, Casella V, Fowler J, Hoffman E, Alavi A, Som P, Sokoloff L. The $\left[{ }^{18} \mathrm{~F}\right]$ fluorodeoxyglucose method for the measurement of local cerebral glucose utilization in man. Circ Res 1979;44:127 37.

[16] Lei KJ, Chen H, Pan CJ, Ward JM, Mosinger BJ, Lee EJ, Westphal H, Mansfield BC, Chou JY. Glucose 6 phosphatase dependent substrate transport in the glycogen storage disease type 1a mouse. Nat Genet 1996;13:203 9.

[17] Zingone A, Hiraiwa H, Pan C J, Lin B, Chen H, Ward J, Chou JY. Correction of glycogen stoage disease type 1a in a mouse model by gene therapy. J Biol Chem 2000;275:828 32.

[18] Siegel S, Vaquero JJ, Aloj L, Seidel J, Jagoda E, Gandler WR, Eckelman WC, Green MV. Initial results from a PET/Planar small animal imaging system. IEEE Transactions on Nuclear Science 1999;46:571 5.

[19] Sadiq HF, deMello DE, Devaskar SU. The effect of intrauterine growth restriction upon fetal and postnatal hepatic glucose transporter and glucokinase proteins. Pediatr Res 1998;43:91 100.

[20] Goldsmith PK, Stetten MR. Different developmental changes in latency for two functions of a single membrane bound enzyme: glucose 6 phosphatase activities as a function of age. Biochim Biophys Acta 1979;583:133 47.

[21] Burchell A, Leakey JE. Development of the rat hepatic microsomal glucose 6 phosphatase system and its glucocorticoid inducibility. Biol Neonate 1988;54:107 15.

[22] Pan CJ, Lei KJ, Chen H, Ward JM, Chou JY. Ontogeny of the murine glucose 6 phosphatase system. Arch Biochem Biophys 1998;358:17 24.

[23] Adams HR, Channing MA, Divel JE, Dunn BB, Kiesewetter DO, Plascjak P, Regdos SL, Simpson NR, Eckelman WC. In: Emran A, editor. Trend analysis of quality control data. New York: Plenum Press; 1995. p. 17588.

[24] Blasberg R, Patlak C, Fenstermacher J. Measurements of blood brain transfer constants for nonmetabolized amino acids. Int Soc Neurochem 1979;7:238.

[25] Patlak CS, Blasberg RG, Fenstermacher JD. Graphical evaluation of blood to brain transfer constants from multiple time uptake data. J Cereb Blood Flow Metab 1983;3:1 7.

[26] Logan J, Fowler JS, Volkow ND, Wang G J, Ding Y S, Alexoff DL. Distribution volume ratios without blood sampling from graphical analysis of PET Data. Journal of Cerebral Blood Flow and Metabolism 1996;16:834 40.

[27] Green LA, Gamghir SS, Srinivasan A, Banerjee PK, Koh CK, Cherry SR, Sharfstein S, Barrio J, Herschman HR, Phelps ME. Noninvasive methods for quantitating blood time activity curves from mouse PET images obtained with fluorine 18 fluorodeoxyglucose. J Nucl Med 1998;39:729 34.

[28] Kallinowski F, Brownell AL, Vaupel P, Brownell GL. Combined tissue oxygen tension measurement and positron emission tomography studies on glucose utilization in oncogene transformed cell line tumour xenografts in nude mice. Br J Radiol 1991;64:350 9.

[29] Hawkins RA, Choi Y, Scates S, Rege S, Hoh CK, Glaspy J, Phelps ME. An animal model for in vivo evaluation of tumor glycolytic rates with positron emission tomography. J Surg Oncol 1993;53:104 9. 
[30] Lapointe D, Brasseur N, Cadorette J, La Madeleine C, Rodrigue S, van Lier JE, Lecomte R. High resolution PET imaging for in vivo monitoring of tumor response after photodynamic therapy in mice. J Nucl Med 1999;40:876 82.

[31] Choi Y, Hawkins RA, Huang SC, Brunken RC, Hoh CK, Messa C, Nitzsche EU, Phelps ME, Schelbert HR. Evaluation of the effect of glucose ingestion and kinetic model configurations of FDG in the normal liver. J Nucl Med 1994;35:818 23.

[32] Hays MT, Segall GM. A mathematical model for the distribution of fluorodeoxyglucose in humans. J Nucl Med 1999;40:1358 66. 